\title{
O apoio matricial e suas relações com a teoria da complexidade
}

\author{
Matrix support and its relations with complexity theory
}

Sanny Rhemann Baeta (https://orcid.org/0000-0003-3296-1335) ${ }^{1}$

Walter Melo (https://orcid.org/0000-0002-5755-0666) ${ }^{1}$

\footnotetext{
${ }^{1}$ Universidade Federal de São João del-Rei. Praça Frei Orlando 170, Centro. 36307-352 São João del-Rei MG Brasil.

sannybaeta@gmail.com
}

\begin{abstract}
The relationships between matrix support and the complexity theory have the Word articulation as a foundantion. Thus, there is a recognition that the notion of matrix support integrates a complex theoretical-methodological arrangement, wich inserts it in the Paideia methodology, placing it in relation to the circular method, the amplified and shared clinic, and the singular therapeutic project (PTS). The technical-assistance and pedagogical character, which characterizes the matrix support, is addressed by the aspect of non-linearity and incompleteness of knowledge, enabling the expansion of the reflective capacity of researches and, in this case, of health professionals.
\end{abstract}

Key words Collective Health, Matrix Support, Complexity Theory
Resumo As relações entre o apoio matricial e a teoria da complexidade possuem a palavra articulação como fundamento. Dessa maneira, há o reconhecimento de que a noção de apoio matricial integra um complexo arranjo teórico-metodológico, que o insere na metodologia Paideia, colocando-o em relação ao método da roda, à clínica ampliada e compartilhada, e ao projeto terapêutico singular (PTS). O caráter técnico-assistencial e pedagógico, que caracteriza o apoio matricial, é abordado pelo aspecto de não-linearidade e de incompletude do conhecimento, possibilitando a ampliação da capacidade reflexiva de pesquisadores e, no caso em questão, de profissionais da saúde.

Palavras-chave Saúde Coletiva, Apoio Matricial, Teoria da Complexidade 


\section{Introdução}

A saúde pode ser concebida a partir de três dimensões: estado vital, setor produtivo e área do saber". O "estado vital" está diretamente relacionado à saúde de um indivíduo e ao modo como conduz sua vida. Assim, pode-se estar saudável ou doente, como também ter hábitos saudáveis ou sedentários. A saúde como "setor" diz respeito à produção de bens e serviços, como unidades de saúde, ambulatórios, hospitais (serviços de saúde), assim como equipamentos, medicações e vacinas (produtos). Mas, a saúde possui, ainda, a dimensão "área do saber", com conhecimentos científicos e populares. Essas três dimensões encontram-se articuladas, por vezes de maneira conflituosa ou criando convergências.

Os estudos dos fundamentos teóricos na área da saúde estão inseridos na dimensão área do saber, mais especificamente na produção de conhecimento científico, pautado em conceitos, sendo efetuados em vários laboratórios de pesquisa das universidades brasileiras, dentre os quais os trabalhos desenvolvidos pela equipe do Núcleo de Estudo, Pesquisa e Intervenção em Saúde (NEPIS), da Universidade Federal de São João del-Rei ${ }^{2-5}$ que, há 12 anos, desenvolve estágios e programas de extensão em instituições de saúde, diversas pesquisas nos âmbitos de Iniciação Científica e de Mestrado e já participou de dois Programas de Educação pelo Trabalho (PET-Saúde). O presente artigo está inserido nas atividades realizadas pelo NEPIS e trata da relação entre dois conceitos: apoio matricial e complexidade.

O apoio matricial foi proposto por Campos ${ }^{6}$ como parte da metodologia Paideia ${ }^{7,8}$. A teoria da complexidade ganha destaque a partir das concepções de Morin ${ }^{9-12}$. A relação entre os dois conceitos foi apontada por Campos ${ }^{13}$, quando afirma que seus esforços em sistematizar conhecimento na área da saúde encontram-se na articulação "das teorias da produção social dos fatos históricos, da complexidade e das concepções de vários autores que estudaram a subjetividade".

Esse esforço de sistematização possui a "articulação" como palavra fundamental: articulação entre aspectos teórico-metodológicos que objetivam a articulação entre profissionais e serviços. Nesse sentido, há articulação entre a metodologia Paideia, o método da roda, o apoio matricial, a clínica ampliada e compartilhada, e o projeto terapêutico singular (PTS).

A metodologia Paideia possui cinco dimensões articuladas: política, gestão, saúde coletiva, clínica e pedagogia ${ }^{7,14}$. Dentre essas dimensões, vamos destacar a clínica e a pedagogia, pois compõem o apoio matricial, que se caracteriza pelo cuidado compartilhado e pela educação permanente $^{15} \mathrm{ou}$, em outras palavras, pelo apoio assistencial e pelo apoio técnico-pedagógico ${ }^{16}$ : "O apoio matricial pretende oferecer tanto retaguarda assistencial quanto suporte técnico-pedagógico às equipes de referência" ${ }^{\prime 17}$.

A concepção Paideia pretende a reorganização do processo de trabalho a partir dos conceitos de cogestão e de clínica ampliada e compartilhada, ou seja, há a "aposta em outra estratégia organizacional e em outra concepção de gestão do trabalho clínico"18. Essa dupla conceituação, por sua vez, serve de base para o apoio matricial $^{19}$. Em relação à gestão dos serviços, o apoio matricial visa à mudança da verticalidade de funcionamento das equipes e dos serviços para uma operacionalização democrática ${ }^{20}$. Essa mudança não acontece, no entanto, de maneira natural. Necessita, portanto, de um método, construído com o objetivo de "repensar o significado e o modo como se organiza o trabalho"20. Esse método está pautado em duplo aspecto: crítica às concepções dominantes e rearranjo dos modos de gestão. Denominado como método da roda, possui três funções: 1) produzir valores de uso a partir de um novo modo administrativo e de planejamento dos processos de trabalho; 2) democratizar as instituições, alterando as formas de exercício de poder; 3 ) interferir na produção de subjetividade a partir da cogestão. Assim, o método da roda apresenta-se como herdeiro de uma longa tradição antitaylorista, rompendo com a verticalidade, com o caráter serial e alienante dos processos de trabalho ${ }^{20}$.

Quando se denomina a clínica como ampliada, tem-se como referência a clínica oficial, em que prevalece $o$ aspecto estritamente biológico e fragmentado, em que ocorre a desresponsabilização pela integralidade dos sujeitos. Então, a pergunta que norteia as práticas de clínica ampliada é: qual o lugar do sujeito na clínica? ${ }^{8}$ Ocorre, portanto, uma ampliação do objeto de conhecimento e de intervenção para além da enfermidade, incluindo o sujeito e seu contexto. Trata-se de estabelecer vínculo com um sujeito concreto, que pensa e sente de maneiras específicas, que possui uma história de vida singular, que está inserido em determinado contexto social, constituído por sua família, seus amigos, seu trabalho, seu bairro etc.

A criação de vínculo, a visão integral e a percepção do sujeito inserido em determinado contexto possibilitam a produção de cuidado de maneira continuada, estabelecendo ações lon- 
gitudinais. A equipe de referência é responsável pelo cuidado contínuo, juntamente com a família e o próprio usuário. Em situações especiais, pode ocorrer a necessidade de atendimentos especializados, sem que se perca a referência, que organiza as ações de saúde. Essas ações podem ser compartilhadas entre membros das equipes de referência e o especialista, garantindo maior troca de conhecimentos e assistência mais integrada. Há, dessa maneira, a superação da lógica de referência e contrarreferência pura e simples ${ }^{21}$. $\mathrm{O}$ apoio matricial favorece, portanto, o cuidado continuado em uma equipe de referência: "Há uma aposta no acolhimento, estabelecimento de vínculos e incentivo à responsabilização compartilhada dos casos como forma de combater a lógica do encaminhamento" 22 .

A clínica ampliada é, portanto, a clínica do sujeito, de um sujeito concreto ${ }^{8}$. Nesse caso, o PTS é a estratégia de intervenção privilegiada, que possui os seguintes recursos: equipe, território, família e o próprio sujeito. A elaboração do projeto é de responsabilidade de todos, incluindo o usuário ${ }^{22}$, tendo como função elaborar diagnóstico, avaliar os riscos, definir as ações e seus responsáveis ${ }^{19}$. Assim, o apoio matricial visa auxiliar a equipe de referência na construção e na execução do PTS de um sujeito que demanda intervenções em saúde, mas que a equipe de referência, a princípio, tenha algum tipo de dificuldade. Nesse encontro entre equipes, há “a possibilidade de discussões coletivas de caso e ao mesmo tempo de uma coordenação, na duração do tempo, das ações desenhadas no projeto" ${ }^{23}$.

Esse compartilhamento coordenado é sustentado pela concepção de planejamento de saúde que leva em consideração "a complexidade da problemática em discussão (evitando reducionismos)"24. A noção de complexidade, por sua vez, não pode ser definida de maneira prévia, sendo construída nos momentos de articulação entre saberes e práticas. Trata-se, portanto, de um exercício, ao qual Edgar Morin ${ }^{9}$ denomina como o "desafio da complexidade". Esse desafio está pautado na "incompletude do conhecimento" e na contextualização de todos os fenômenos ${ }^{12}$. Desafio ampliado quando a área do conhecimento é a saúde, mais ainda no Brasil, país de imensas desigualdades econômicas e educacionais.

\section{Aspectos da não-linearidade e da incompletude do conhecimento}

De acordo com Morin ${ }^{10}$, os problemas que a realidade apresenta são multidimensionais e polidisciplinares, enquanto os saberes produzidos e as práticas efetuadas são fragmentados e compartimentados. Essa enorme discrepância faz com que o aspecto plural dos fenômenos seja reduzido e segmentado. A hiperespecialização, tão presente e valorizada em nossa época, evidencia esse processo e estado atual de nosso conhecimento.

O sistema de educação tradicional desenvolve um processo de formação do conhecimento que impõe à complexidade das relações uma redução aos elementos mais simples, a separação do que se encontra articulado e a unificação do que é múltiplo, gerando contradições e desordem ao pensamento. Esse tipo de inteligência "reduz o caráter complexo do mundo a fragmentos desunidos, fraciona os problemas e unidimensionaliza o multidimensional (...) termina a maior parte das vezes por ser cega, porque destrói todas as possibilidades de compreensão e reflexão, eliminando na raiz as possibilidades de um juízo crítico e também as oportunidades de um juízo corretivo ou de uma visão a longo prazo" ${ }^{11}$.

Essa segmentação do conhecimento faz com que o saber seja cada vez mais esotérico, ou seja, reservado apenas aos especialistas, excluindo os demais cidadãos do seu direito ao saber. $\mathrm{O}$ fato é que o especialista, usufruindo de seu saber fragmentado, desempenha bem as suas funções em setores compartimentados. No entanto, em situações complexas, como a saúde, ocorre a incapacidade de compreender as interações, inter -retroações e a causalidade circular, pois tende a conceber os fenômenos vivos e sociais de forma mecanicista e em causalidade linear. Esse conhecimento fragmentado e fragmentário faz com que o especialista perca a capacidade de conceber o global e o cidadão perca o direito ao conhecimento ${ }^{10-12}$.

Enquanto fator de segmentação, a divisão do conhecimento em disciplinas compromete a noção de complexidade. A disciplina é a categoria organizadora do conhecimento científico atual, instituindo a divisão e a especialização do trabalho, por meio de linguagem e tecnicismo próprios. As fronteiras disciplinares se enrijecem e cada conhecimento se fecha em si mesmo, perdendo a comunicação com os demais. A disciplinaridade é um fator de delimitação dos domínios de competência, sem o qual o conhecimento tornar-se-ia vago e fluído. Além disso, cria condi- 
ções para se desvendar, extrair ou construir "um objeto digno de interesse para o estudo científico" ${ }^{\prime 1}$. Por outro lado, a disciplina pode implicar, simultaneamente, no risco de hiperespecialização do profissional e de coisificação do sujeito, pois, o olhar fragmentado induz à percepção de um objeto pronto, desconsiderando-o em seu caráter processual, elaborado em determinado contexto. Prisioneiro dos limites disciplinares, o profissional não consegue rompê-los e, tampouco, perceber as relações de seu objeto de estudo com o universo e com os demais objetos estudados por outras disciplinas.

O desafio da complexidade é, também, o desafio da globalidade, entendida como a relação entre a parte e o todo ${ }^{12}$. Essa articulação entre componentes que são inseparáveis constituem "um tecido interdependente, interativo e inter -retroativo entre as partes e o todo, o todo e as partes"10. Esse conhecimento pautado na não-linearidade evidencia a necessidade de abertura das fronteiras, ou melhor, da transformação dos princípios organizadores do conhecimento que as estabelecem, de tal forma a interligar as disciplinas $^{10,11}$. O autor afirma que, por vezes, essa abertura advém do olhar de um leigo ou amador que desconhece a disciplina e, portanto, não se encontra limitado a esta e nem aos obstáculos construídos pela própria teoria. Assim, ele se torna capaz de propor uma solução possível para um impasse cuja disciplina, com seus conceitos e técnicas, não pôde solucionar. Percebe-se que os especialistas, ao serem convocados a colaborarem na resolução dos problemas e, pelo fato de terem sido formados dentro do paradigma da disjunção, são capazes apenas de analisar tais situações dentro de suas perspectivas disciplinares, não identificando as múltiplas facetas e tampouco os sinais emitidos por esses problemas. Consequentemente, esses especialistas sugerem soluções parciais ou inadequadas que não atingem, de fato, as causas reais ${ }^{11,25}$.

É importante frisar que, quando Morin ${ }^{11}$ propõe a ruptura do isolamento entre as disciplinas, não está defendendo a ideia de desordem, da dissolução organizativa dessas e/ou que descartemos tudo aquilo já criado por elas. Ele propõe que consideremos que uma disciplina deve ser, ao mesmo tempo, aberta e fechada, pois os conhecimentos produzidos além de suas fronteiras também lhe são necessários para que não se torne automatizada e estéril. Propõe, ainda, que as disciplinas sejam concebidas nos seus múltiplos aspectos de uma realidade complexa, pois somente assim os profissionais poderão adquirir um conhecimento global em relação ao seu objeto de estudo ${ }^{11}$.

Esse caráter de incompletude do conhecimento possibilita que pesquisadores e profissionais, como os da saúde, se coloquem em movimento de articulação, de maneira multi, inter ou transdisciplinar. A "multidisciplinaridade" refere-se a uma associação de disciplinas que atuam em torno de um projeto ou de um objeto, que lhes é comum e, para o qual, essas disciplinas, bem como os seus técnicos especialistas, podem colaborar em prol da solução de um determinado problema. Por "interdisciplinaridade" entende-se o conjunto de disciplinas distintas, em que cada qual afirma os seus próprios conceitos, direitos e primazias em relação às exigências das demais disciplinas, podendo haver trocas e cooperação, na tentativa de superar a fragmentação. A "transdisciplinaridade", por sua vez, refere-se à possibilidade de comunicação entre as disciplinas através de uma unidade de conhecimento, que se caracteriza pelos esquemas cognitivos que as permeiam ${ }^{11}$.

As características apontadas por Morin ${ }^{9,10,12}$, de não-linearidade e incompletude do conhecimento, servem de sustentação ao conceito de apoio matricial, que faz parte de uma articulação conceitual que propicia a interação entre diversos profissionais. Sabe-se que o apoio matricial é um modelo colaborativo em saúde e pressupõe que os núcleos de experiências e saberes específicos de cada profissional possam ser compartilhados, de modo a atuar, sinergicamente, em prol da melhoria das condições de vida dos sujeitos, assim como validar a construção de novos saberes e práticas no campo da saúde ${ }^{23}$. Diante disso, compreende-se que as propostas do apoio matricial vão ao encontro das ideias formuladas por Morin em sua teoria da complexidade.

\section{Articulação, apoio e contextualização}

Como vimos na introdução, a noção de apoio matricial está articulada, de maneira não-linear, a diversas construções teóricas. Essa articulação teórica é, em verdade, uma aposta no poder de articulação entre profissionais de diferentes áreas do conhecimento e de diferentes serviços, visando "ampliar a capacidade de resolver problemas de saúde, considerando a gênese complexa desses fenômenos" ${ }^{\prime \prime}$. Para pensarmos a relação entre a noção de apoio matricial com a teoria da complexidade, desenvolvemos os aspectos centrais da reforma do pensamento pautada na não-linearidade e incompletude do conhecimento ${ }^{10}$. Nesse 
sentido, o pensamento complexo é tido como relativo e contextual ${ }^{26}$, impulsionando ao apoio técnico assistencial e ao apoio pedagógico de maneira contextualizada.

O termo "apoio matricial" é composto por dois conceitos operadores: "apoio" que sugere uma metodologia de ordenação entre referência e especialista, não baseada na autoridade (relação vertical), mas nos procedimentos dialógicos (relação horizontal); e "matricial" que advém de "matriz" e tanto pode indicar um lugar de criação quanto um núcleo onde determinados valores ou conceitos coexistem entre $\mathrm{si}^{17,24}$.

$\mathrm{O}$ apoio matricial pode ser compreendido, portanto, enquanto um arranjo organizacional e também como uma metodologia que considera a integralidade nos seus variados aspectos, pois possibilita que os diversos núcleos de saberes sejam compartilhados dialogicamente entre os profissionais especialistas (apoiadores matriciais) e os que compõem a equipe de referência. Assim, o apoio matricial contribui, também, para a ampliação do trabalho clínico e sanitário, pois nenhum especialista, isoladamente, pode assegurar a abordagem integral de um determinado sujeito ${ }^{17,27,28}$.

Ao compreendermos a saúde, em seus diversos aspectos, e o apoio matricial de maneira complexa, entendemos a necessidade de condições que possibilitem a operacionalização desse arranjo técnico-pedagógico: "número e qualificação dos profissionais disponíveis; necessidade de qualificação dos profissionais envolvidos; cultura organizacional dos gestores e dos trabalhadores envolvidos; rede de serviços disponível; organização do processo de trabalho nos serviços"23. Essas condições dizem respeito a questões referentes à formação universitária, à educação continuada, à gestão, à organização da rede de saúde e ao processo de trabalho. Cada tópico considerado separadamente implica em um conjunto de saberes e práticas de extrema complexidade. Essas condições se apresentam de maneira conjunta e interligada, ampliando o grau de complexidade.

O fundamento do apoio matricial está no encontro entre profissionais de uma equipe de referência e de áreas especializadas ${ }^{16}$. Essa atuação conjunta possibilita um aprimoramento na assistência a determinado usuário e na intensificação da troca de conhecimentos. Dessa forma, a retaguarda assistencial do apoio matricial produzirá uma ação clínica direta em relação ao sujeito em questão, ao passo que o suporte técnico-pedagógico produzirá uma ação educativa nas equipes ${ }^{24}$. No entanto, os papéis de apoiador e de apoiado não são fixos, pois um profissional pode ser re- ferência técnica em uma situação e deter um conhecimento especializado em outra, sendo essa a principal diferença entre o apoio matricial e a interconsulta ${ }^{19}$. Além disso, o apoio matricial visa implementar a cogestão nas relações interprofissionais, na tentativa de superação das relações burocratizadas e de poder. Nesse sentido, a partir do apoio matricial pode-se elaborar uma crítica à interconsulta, sem, no entanto, abandoná-la, mas propondo uma reconfiguração pautada na lógica da cogestão ${ }^{8}$. Assim, a ênfase não está nos lugares ocupados, referência ou especialista, mas na relação que se estabelece.

$\mathrm{O}$ apoio matricial implica sempre na construção de um projeto terapêutico integrado e este, por sua vez, na possibilidade de discussões coletivas de casos e na execução das propostas do projeto $^{24}$. A articulação entre a equipe de referência e os apoiadores matriciais pode ser desenvolvida, de acordo com Campos ${ }^{6}$, em três planos fundamentais: a) atendimentos e intervenções conjuntas, isto é, realização de interconsultas e visitas domiciliares; b) situações específicas à matriz de conhecimento do apoiador, podendo este realizar intervenções e atendimentos, além de manter-se em contato com a equipe de referência que, por sua vez, não deve se desresponsabilizar do caso, oferecendo-lhe os cuidados complementares; c) compartilhar os seus conhecimentos e orientações, discutindo as condutas que digam respeito ao caso em estudo, mas este permanecendo sob os cuidados da equipe de referência. Além dos aspectos mencionados, o apoio matricial cumpre outra importante função: a regulação do fluxo de usuário na rede de saúde, a fim de romper com a lógica hierárquica e burocratizada de atendimentos, pautada nos mecanismos de referência e contrarreferência, protocolos e centros de regulação ${ }^{6}$.

Através de ações e saberes compartilhados, o apoio matricial propicia a ampliação da capacidade reflexiva, de compreensão e de intervenção. O exercício da reflexão aproxima-nos da complexidade da gênese e da multiplicidade de efeitos dos fatos sociais, que, em seu caráter processual, são afetados por uma variedade de elementos ${ }^{8}$. O apoio matricial se coloca, assim, na contramão do saber biomédico hegemônico. De acordo com Morin $^{10}$, para tentar compreender fenômenos variados, como a saúde, ocorreu uma expansão descontrolada do saber, em que o crescimento vertiginoso de conhecimentos provoca um acúmulo de linguagens discordantes, propiciando exatamente o contrário do que se pretendia.

Por outro lado, o apoio matricial se coloca em consonância com as proposições da teoria 
da complexidade. Nesta, o conhecimento, para assim ser considerado, deve ser organizado e contextualizado, ou seja, deve ser global, pois conhecimentos fragmentados não contribuem para a formação de um pensamento capaz de conceber a vida em sua complexidade. O enfraquecimento da percepção global compromete o senso de responsabilidade e de solidariedade, visto que cada sujeito, ao se responsabilizar apenas por sua especialidade, desconsidera o seu vínculo com a sociedade, com os outros cidadãos e com a democracia $^{10}$.

\section{Considerações finais}

O desafio da complexidade pode ser entendido como o desafio do apoio matricial. O encontro entre profissionais deve proporcionar a troca de conhecimentos e a ampliação da capacidade reflexiva. Esse tipo de proposta parte do reconhecimento de que a saúde é um fenômeno complexo em construção. A produção de conhecimento acontece de maneira não-linear e sempre se mostra incompleta. A articulação entre conceitos, metodologias, profissionais, serviços, somente é possível pela reforma do pensamento. A "cabeça bem-feita" ${ }^{10}$ refere-se à capacidade de conceber $\mathrm{o}$ complexo, fazendo inter-relações entre o global e o local, entre o todo e as partes, ou seja, trata-se da capacidade de conectar o que está separado.

Na saúde, a complexidade dos fenômenos é evidenciada na capacidade de perceber o sujeito de maneira integral, considerando os diversos fatores que o compõem e que, por outro lado, sofrem sua interferência. $\mathrm{O}$ mesmo podemos dizer sobre a capacidade de trabalhar em equipe e de articular uma rede de cuidados. Isso depende da constatação de que todo saber é limitado diante da complexidade que é a vida de determinado sujeito. Esse reconhecimento é a base para mobilizar os profissionais para ações conjuntas, compartilhando conhecimentos.

Desse modo, para não correr o risco de segmentar o sujeito, abordando-o apenas pelo viés de sua disciplina de formação, o profissional opta por convocar os demais profissionais e seus respectivos saberes para comporem, juntos e de modo dialético, as intervenções mais adequadas àquele sujeito. As concepções de apoio matricial e da teoria da complexidade problematizam a fragmentação do conhecimento e a verticalização das relações. Nesse sentido, a articulação entre essas duas propostas permite ampliar o espectro de discussões no campo da saúde, marcado por fundamentos políticos, teóricos, metodológicos e técnicos que lhes são inerentes, pois "o objetivo do conhecimento é abrir, e não fechar o diálogo".

\section{Colaboradores}

SR Baeta foi responsável pela pesquisa, metodologia e formatação do manuscrito e W Melo trabalhou na concepção e na redação final do mesmo. 


\section{Referências}

1. Paim JS. O que é o SUS. Rio de Janeiro: Fiocruz; 2009.

2. Araújo CB. Centro de Referência de Assistência Social (Cras), Estratégia Saúde da Família (ESF) e educação básica: como vai a intersetorialidade? [dissertação]. São João Del Rei: Universidade Federal de São João Del-Rei; 2014.

3. Baeta SR. A articulação entre serviços de atenção básica e o Caps-ad III no município de Barbacena-MG: dificultadores e facilitadores [dissertação]. São João Del -Rei: Universidade Federal de São João Del-Rei; 2016.

4. Cézar MA. Políticas públicas de saúde mental e o cotidiano dos serviços substitutivos: um estudo sobre ideologia na Reforma Psiquiátrica brasileira [dissertação]. São João Del-Rei: Universidade Federal de São João Del-Rei; 2014.

5. Melo W. As regiões de fronteiras do Espaço Artaud: articulações entre saúde e cultura. Pesq Práticas Psicossociais 2012; 7(2):211-222.

6. Campos GWS. Equipes de referência e apoio especializado matricial: um ensaio sobre a reorganização do trabalho em saúde. Cien Saude Colet 1999; 4(2):393403.

7. Campos GWS. Saúde Paidéia. São Paulo: Hucitec; 2003.

8. Campos GWS, Cunha GT, Figueiredo MD. Práxis e formação Paideia: apoio e cogestão em saúde. São Paulo: Hucitec; 2013.

9. Morin E. Ciência com consciência. Rio de Janeiro: Bertrand Brasi; 2005.

10. Morin E. A cabeça bem-feita: repensar a reforma, reformar o pensamento. Rio de Janeiro: Bertrand Brasil; 2007.

11. Morin E. Educação e complexidade: os sete saberes e outros ensaios. São Paulo: Cortez; 2013.

12. Morin E. Penser global. Paris: Robert Laffont; 2015.

13. Campos GWS. Clínica e saúde coletiva compartilhadas: teoria Paidéia e reformulação ampliada do trabalho em saúde. In: Campos GWS, Minayo MCS, Akerman M, Drumond Júnior M, Carvalho YM. Tratado de saúde coletiva. São Paulo: Hucitec; Rio de Janeiro: Fiocruz; 2006. p. 53-92.

14. Soeiro E, Oliveira JM, Malvezzi E, Gigante RL. Tecnologia e inovação na gestão do cuidado: o apoio matricial na ampliação da clínica e formação de profissionais em saúde. In: Campos GWS, Castro CP, Fernandes JA, Anéas TV, organizadores. Investigação sobre cogestão, apoio institucional e apoio matricial no SUS. São Paulo: Hucitec: Fapesp; 2017. p. 141-175.

15. Castro CP. Apoio matricial no SUS Campinas: a construção de práticas compartilhadas. In: Campos GWS, Castro CP, Fernandes JA, Anéas TV, organizadores. Investigação sobre cogestão, apoio institucional e apoio matricial no SUS. São Paulo: Hucitec: Fapes; 2017. p. $112-140$

16. Anéas TV. Apoio matricial dos Núcleos de Apoio à Saúde da Família (Nasf): uma análise da região norte do município de São Paulo. In: Campos GWS, Castro CP, Fernandes JA, Anéas TV, organizadores. Investigação sobre cogestão, apoio institucional e apoio matricial no SUS. São Paulo: Hucitec: Fapesp; 2017. p. 176-207.
17. Campos GWS, Domitti AC. Apoio matricial e equipe de referência: uma metodologia para gestão do trabalho interdisciplinar em saúde. Cad Saude Publica 2007; 23(2):399-407.

18. Campos GWS, Amaral MA. A clínica ampliada e compartilhada, a gestão democrática e redes de atenção com referenciais teórico-operacionais para a reforma do hospital. Cien Saude Colet 2007; 12(4):849-859.

19. Campos GWS. Projeto terapêutico e estratégias de promoção em situações de apoio matricial. In: Campos GWS, Castro CP, Fernandes JA, Anéas TV, organizadores. Investigação sobre cogestão, apoio institucional e apoio matricial no SUS. São Paulo: Hucitec: Fapesp; 2017. p. 103-111.

20. Campos GWS. Um método para análise e co-gestão de coletivos: a constituição do sujeito, a produção de valor de uso e a democracia em instituições - o método da roda. São Paulo: Hucitec; 2000.

21. Chiaverini $\mathrm{DH}$, organizadora. Guia prático de matriciamento em saúde mental. Brasília: MS/Centro de Estudo e Pesquisa em Saúde Coletiva; 2011.

22. Onocko-Campos R, Gama C. Saúde mental na atenção básica. In: Campos GWS, Guerrero AVP, organizadores. Manual de práticas de atenção básica, saúde ampliada e compartilhada. São Paulo: Hucitec; 2013. p. 221-246.

23. Oliveira GN. Apoio matricial como tecnologia de gestão e articulação em rede. In: Campos GWS, Guerrero AVP, organizadores. Manual de práticas de atenção básica, saúde ampliada e compartilhada. São Paulo: Hucitec; 2013. p. 273-282.

24. Oliveira GN. O projeto terapêutico e a mudança nos modos de produzir saúde. São Paulo: Hucitec; 2010.

25. Westphal MF, Mendes R. Cidade saudável: uma experiência de interdisciplinaridade e intersetorialidade. Rev Admin Pública 2000; 34(6):47-61.

26. Almeida Filho N. A saúde e o paradigma da complexidade. São Leopoldo: Unisinos; 2004.

27. Fortes S. Saúde mental na atenção primária: matriciamento e a supervisão clínico-institucional. In: Nunes Filho A, organizador. Supervisão em saúde mental. Belo Horizonte: ESP; 2013. p. 86-99.

28. Brasil. Ministério da Saúde (MS). Diretrizes do Nasf: Núcleo de Apoio à Saúde da Família. Cadernos de Atenção Básica $n^{\circ}$ 27. Brasília: Secretaria de Atenção à Saúde, Departamento de Atenção Básica: 2006.
Artigo apresentado em 06/02/2018

Aprovado em 11/09/2018

Versão final apresentada em 13/09/2018 
